\title{
Critical Remarks on Some Business-Cycle Theories
}

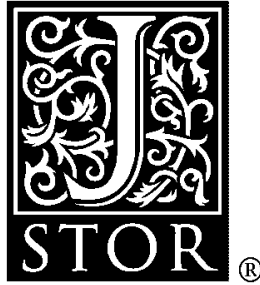

\section{J. Tinbergen}

Econometrica, Vol. 10, No. 2. (Apr., 1942), pp. 129-146.

Stable URL:

http://links.jstor.org/sici?sici=0012-9682\%28194204\%2910\%3A2\%3C129\%3ACROSBT\%3E2.0.CO\%3B2-0

Econometrica is currently published by The Econometric Society.

Your use of the JSTOR archive indicates your acceptance of JSTOR's Terms and Conditions of Use, available at

http://www.jstor.org/about/terms.html. JSTOR's Terms and Conditions of Use provides, in part, that unless you have obtained prior permission, you may not download an entire issue of a journal or multiple copies of articles, and you may use content in the JSTOR archive only for your personal, non-commercial use.

Please contact the publisher regarding any further use of this work. Publisher contact information may be obtained at http://www.jstor.org/journals/econosoc.html.

Each copy of any part of a JSTOR transmission must contain the same copyright notice that appears on the screen or printed page of such transmission.

JSTOR is an independent not-for-profit organization dedicated to and preserving a digital archive of scholarly journals. For more information regarding JSTOR, please contact support@jstor.org. 


\title{
CRITICAL REMARKS ON SOME BUSINESS-CYCLE THEORIES
}

\author{
By J. TinBergen
}

\section{A. INTRODUCTORY}

In PREvious INVESTIGations ${ }^{1}$ we have attempted, with the help of statistical methods, to contribute to the explanation of cyclical fluctuations in modern free-enterprise economies, viz., the United States and Holland, 1921-1932. The experience gathered has since been increased by a yet unpublished study of the same type of the British economy in the period 1870-1914. In the present paper we propose to consider critically some of the best-known business-cycle theories in the light of the results of these investigations. We shall not base our observations solely on statistical arguments, however, but also make use, where that seems appropriate, of other considerations.

We do not claim to have proved, when constructing our models of the American, English, and Dutch economies, all features laid down in these models to be inevitable. We have presented these models as possible structures, perhaps even as probable structures, which have the advantage that they are at least not contradictory to the statistics used in their construction. Hence, not all our conclusions on some business-cycle theories can actually be proved. Nevertheless we think that our attempts lead to useful suggestions and it is hoped that those who reject our conclusions will at least try to give alternative attempts to explain the real course of the crucial variables in a way similar to ours.

The ultimate scope of a paper like the present would be that we could state for any theory: i. whether or not it is in accordance with the facts, and ii. if it were true, to what extent it explains the course of events. The decision that a theory is true (cf. point $\mathrm{i}$ above) can only be taken on the basis of economic arguments, but provided that the statistician has found it not to be contradictory to the facts. That decision once taken, the statistician may again take over the job and tell (cf. point ii above) to what extent it influences the course of events.

We shall not, however, be able to proceed in accordance with this ideal. As far as possible we shall try to approach it.

As a rule, a theory contains two sorts of statements, first, statements on elementary equations, and secondly, statements on the combined effect of elementary equations. Statements on elementary equations deal with the direct causes of the fluctuations in one of the economic

${ }^{1} \mathrm{~J}$. Tinbergen, Business Cycles in the United States, 1919-1932, Geneva, League of Nations, 1939, to be quoted as U.S.; and An Econometric Approach to Business Cycle Problems (relating to Holland), Paris, Hermann, 1937, to be quoted as Holl. 
phenomena of the mechanism. Statements on the combined effect of more than one elementary equation relate to the indirect causes and, when going far enough, give an insight into the general process of movement of the system. The elementary equations are the elements upon which all further deduction has to be built.

When reviewing, in the following sections, some theories, we shall, for each important statement on some elementary equation made by that theory, try to

(a) indicate whether or not any direct cause, mentioned by that theory, has been included in our calculations;

(b) if not, give the reasons why it was not included;

(c) if included, state whether or not we found it to be important.

Some scattered remarks on the combined effect of the elementary relations will be added. In some cases an immediate testing of the statements made by some theories is possible.

\section{B. MONETARY OVERINVESTMENT THEORIES}

Haberler ${ }^{2}$ considers as the characteristic feature of all overinvestment theories that they stress the fact of the overdevelopment, during the boom, of investment-goods industries as compared with consumers'goods industries. It may already be observed at the start that this fact may best be illustrated by the relative amplitudes of the production curves for both types of industries, i.e., by the amplitudes expressed as a percentage of trend values. It is not true, as is sometimes thought, that the absolute fluctuations in the volume or the value of production are larger for investment-goods industries than for consumers'-goods industries. ${ }^{3}$

The group of overinvestment theories is subdivided by Haberler into three groups, viz., (a) monetary theories, (b) nonmonetary theories, and (c) theories using the acceleration principle. According to group (a), the business cycle is not a purely monetary phenomenon, but some authors consider monetary forces as the impelling factor (the disturbing shock in our words), others believe that certain monetary arrangements are conditioning factors. ${ }^{4}$ In this section we shall consider the relations and conclusions put forward by the theories of group (a).

1. An elastic money supply is assumed to exist. ${ }^{5}$ This is confirmed by

${ }^{2}$ Prosperity and Depression, New revised and enlarged edition, Geneva, League of Nations, 1939, Ch. 3.

${ }^{3}$ For the U. S. we find, e.g., that the value of production of consumers' goods falls from 1929 to 1932 by $\$ 30,000$ million, the value of production of investment goods by $\$ 15,000$ millions (U.S., p. 206). For the U.K. the standard deviations from trend are $£ 50$ and $£ 20$ millions respectively.

4 Haberler, op. cit., p. 31.

s Ibid., p. 33. 
our results for the United Kingdom where we found the supply of bank notes to be fairly elastic and that of bank deposits to be very elastic. For the United States the elasticity of supply is found to be $0.65 .{ }^{6} \mathrm{It}$ is interesting to note that if the money supply were completely elastic, this would mean that the other (nonmonetary) factors were allowed to work out completely, without being hindered in any way by the monetary system. Thus, in a sense, a complete elasticity of the money supply means that the shape and length, etc., of the cycles depend only on nonmonetary factors and in this sense are a nonmonetary phenomenon. On the other hand, this complete elasticity of the money supply means that the monetary condition is fulfilled for the free development of the cycle. Some authors seem to base their statement that "cycles are a monetary phenomenon" on this consideration. Thus there seems to be some confusion as to the exact meaning of a "monetary phenomenon" and it seems better to speak in such concrete terms as "high elasticity of money supply," etc.

2. Much importance is attached to the distinction of market rate of interest and natural rate of interest; the demand for investable funds is assumed to depend on the difference between market rate and natural rate. $^{7}$ The market rate is assumed to be influenced more or less deliberately by the banking authorities. The following comments may be given:

(a) The concept of natural rate is not so clear as most theorists suggest to us. Usually it is introduced as the interest rate that would equate demand for investable funds and supply of savings, credit creation being excluded. At closer inspection this is not so unambiguous as it seems to be. Clearly it is a hypothetical rate; hence it depends on the assumptions made. It must not be overlooked that both the demand for investable funds and the supply of savings may depend, directly or indirectly, on the rate of interest. That they may depend directly on it will be clear. They also depend indirectly on it, for the simple reason that all economic phenomena are interrelated. If the supposed equilibrium between demand for investable funds and savings should be realized, the interest rate would change and this would also change the demand and the savings. A perfect equilibrium would be obtained only if all indirect influences of the new interest rate should also have worked out; more or less provisional equilibria would be conceivable if not all indirect influences should have worked out yet. Now there may be made all sorts of hypotheses on whether or not the various indirect

${ }^{6}$ This may be calculated from U.S., page 88 , where it is found that $d M / d m_{s}$ $=6.6$. According to the tables on p. 205 the average value for $M$ is 47.8 and for $m_{\mathrm{s}}$ is 4.7. It follows that the elasticity is $\mathbf{0 . 6 5}$.

${ }^{7}$ Haberler, op. cit., p. 34. 
influences of the change in interest rate have to be included or not in the concept of natural rate. ${ }^{8}$

(b) If it is already uncertain what the exact definition of the natural rate should be, then its statistical measurement is still more uncertain and it is not very probable that entrepreneurs would base their investment plans on it. Sometimes it is identified with the current profit rate. It would be difficult to prove that this identification is in accordance with one of the possible definitions, unless a number of simplifying assumptions be introduced. But there is a good deal of common sense in the assumptions that (i) investment activity depends on the difference between expected profit rate and market rate of interest and (ii) the expected profit rate goes up and down parallel with the current profit rate.

(c) Our results ${ }^{9}$ show that a reasonable degree of accordance with the facts can be obtained if profits, the interest rate, and the price of investment goods are assumed to be the factors determining investment activity. The reason why the price of investment goods is also introduced has been set out in previous work of the author. ${ }^{10}$ Figures for profit rates are not available, but similar calculations have been made for the period 1919-1936 and for Germany, 1870-1912, where figures for profit rates were available. In these cases it was found that, in fact, the regression coefficients found for profit rates and interest rates were about equal and of opposite sign, meaning that it is by the difference between both rates that they influence investment activity. ${ }^{11}$ At the same time all calculations mentioned show that the fluctuations in profits are, by their greater amplitude, much more responsible for the investment fluctuations than those in the market interest rate. Our results would therefore suggest that an explanation of the fluctuations in investment activity must emphasize much more the fluctuations in natural rates - as far as those may be identified with profit rates-than those in market rates, as is also suggested by Haberler.

(d) This conclusion is the more acceptable, since it is questionable whether market interest rates are, to such a large extent as some theorists would make us believe, dependent on deliberate action of the bankers. Mr. Hawtrey's thesis that they are largely determined on the basis of the gold stock and its probable changes is in conflict with this view; and our calculations do not challenge Mr. Hawtrey's opinion. Both for the United States and the United Kingdom the fluctuations

8 The clearest discussion on this matter is found, as far as I know, in Professor Frisch's mimeographed lectures.

${ }^{9}$ A Method and Its Application to Investment Activity, Geneva, 1939.

${ }^{10}$ Ibid., p. 36.

11 Ibid., p. 66 . 
in the short-term rate of interest can be well explained by the fluctuations in gold stock of the central banks. For the case of the United Kingdom account has to be taken of some supplementary factors relating to the tension in the balance of payments. Quite generally the wellknown fact that interest rates move closely parallel to the general cycle and somewhat lagged ${ }^{12}$ is an additional argument against the view that deliberate action of the banks determines them.

3. Low interest rates are assumed to stimulate investment activity, incomes, and prices. All this does not conflict with our statistical results; the influence on investment activity has been mentioned already. The influence of investment activity on incomes is generally recognized and also reflected in our models ${ }^{13}$ and so is the influence of activity on prices. ${ }^{14}$ It should not be forgotten, however, that, if the explanation given of investment activity is correct, the influence of interest rates on investment activity is rather small and hence also the indirect influence on the other phenomena.

4. As a counterpart to the influence of interest rates on prices, the influence of rising prices on interest rates is stressed by pointing to the advantages obtainable by commodity speculation. ${ }^{15}$ By our method, a clear direct influence of the rate of increase in prices on the demand for goods could not be discerned. Two attempts have been made. The rate of increase in prices of investment goods was included as one of the explanatory variables in the explanation of investment activity. ${ }^{16}$ It turned out to have a weak influence only. In the "explanation" of consumption outlay for the United Kingdom both $p$ (cost of living) and $p_{-1}$ (cost of living, one year before) were included and the latter got a very small regression coefficient. If an influence of the rate of increase, $p-p_{-1}$, had been present, $p_{-1}$ ought to have obtained a large negative coefficient. So a direct influence of the rate of increase in prices on the demand for goods could not be discerned. Of course such statements always depend on what other variables have been included in the correlation analysis; these other variables, however, do seem to have been chosen reasonably.

An indirect influence of the rate of increase in prices was, however, found, at least for the United Kingdom and Holland, since incomes themselves could be "explained" satisfactorily only if they were as-

12 This fact has led to the construction of the $C$-curve of the Harvard barometer, which, as the reader knows, was based primarily on observation without a particular theoretical background.

${ }^{13}$ U.S., eq. (5. 10); Holl., Ch. I, G.

14 U.S., Ch. III; Holl., p. 16.

${ }^{15}$ Haberler, op. cit., p. 37.

${ }_{16}$ Tinbergen, A Method..., pp. $51 \mathrm{ff}$. 
sumed to depend on the rate of increase in prices. ${ }^{17}$ This represents the fact that "paper profits" on commodity stocks are included in profits calculations. Since profits influence, in their turn, the demand for both consumers' goods and investment goods, there would exist an indirect influence of the rate of increase in prices on the demand for goods and hence for credits. The demand for credits influences the interest rate. Thus there would be, also according to our scheme, an influence of the rate of increase in prices on the interest rate.

5. Considerable importance is attached, by the theories under discussion, to the changes in the real sphere as a consequence of an increased investment activity. ${ }^{18} \mathrm{It}$ is held that by the fall in the rate of interest the roundabout way of production is lengthened, which means a relative increase in the production of investment goods as compared with consumers' goods. Before commenting from the statistical side, we have to make some observations from a theoretical viewpoint. The length of the roundabout way can be determined only for a state of equilibrium. It may then, in our models, be represented by the ratio of the production of investment goods to that of consumers' goods; but the production of investment goods has to represent the production that is actually necessary and sufficient for the maintenance of the level of production of consumers' goods at a given level. If, however, the production of consumers' goods is not constant through time, the quantity of investment goods necessary for that production is not constant either and the annual replacement production of investment goods may fluctuate in a still different way. Year-to-year changes in the ratio need not have anything to do with changes in the roundabout way. This conclusion is reinforced by the existence of new investment, which may fluctuate because of exaggerated expectations. Thus it can hardly be proved from the facts whether or not the roundabout way of production for any given product shows cyclic movements. On the other hand, the fluctuations in the ratio may well be explained by other and simpler relationships, viz., the fact that profit fluctuations have a larger infiuence on the demand for investment goods than on the demand for consumers' goods.

There are also some a priori reasons to suppose that the changes in roundabout way of production during the cycle are only faint. Because of the long lifetime of most investment goods, only a relatively small part of them can be replaced, during any one year, by other types, in accordance with the prevailing rate of interest. Although, therefore, the

${ }^{17}$ For the U.S. this could not be discerned; perhaps since in that case the fluctuations in volume of production were more important than in the other cases. Thus the price changes did not take such an important place in the fluctuations in profits as in the case of the U.K.

18 Haberler, op. cit., p. 39. 
statement of the cyclic fluctuations in the roundabout way cannot be tested statistically with the material at hand, there are good reasons to neglect this phenomenon altogether.

This does not mean, as we said already, that the ratio between the production of investment goods and that of consumers' goods does not change. It certainly fluctuates during the cycle; it is high in boom periods and low in depressions. The two production series hardly show, however, as is sometimes thought, a lag. ${ }^{19}$ Both series are, in our equations, regulated chiefly by the fluctuations in profits; the production of consumers' goods is connected with them by the marginal propensity to consume and the production of investment goods by a coefficient that similarly could be called the marginal propensity to invest. The relative magnitude of these two coefficients appears to be such that the resulting fluctuations in investment activity are, on a percentage basis, larger than those in the production of consumers' goods. It does not seem satisfactory to end our interpretation at this point, since various authors in this field try to explain this relative magnitude. One explanation is that of the acceleration principle, to which we shall pay attention afterwards. For long-run changes this is certainly right-it is almost a tautology-but for short-run changes it appears not to be true. ${ }^{20} \mathrm{An}$ other explanation is the Keynesian, where the propensity to invest is identified with the propensity to save, by the neglect of a lag (which may be short) and the ratio between the two production series is, therefore, chiefly determined by the level of the marginal propensity to consume. Our own attitude is largely affirmative to Mr. Keynes' view, with a slight reservation for the neglect of the lag and for the possibility of investing abroad. This latter point is not in conflict with Mr. Keynes' theory, but with an application to an open country.

6. The proximate causes for the downturn. ${ }^{21}$ Before considering the particular causes of the downturn, we may repeat a general statement of, in our opinion, primordial importance to the questions now under discussion. The question whether or not a downturn will occur is a quantitative question. With the same qualitative connections between the phenomena studied, a downturn may inevitably develop in the case of one set of coefficients and inevitably not develop with another set of coefficients. These questions cannot be understood without a quantitative study of the connections. ${ }^{22}$

${ }^{19}$ Cf. also my "Suggestions on Quantitative Business Cycle Theory," EconoMETricA, Vol. 3, 1935, p. 241, in particular pp. 253-254, and "Consumptiegoederen en productiemiddelen," De Nederlandsche Conjunctuur, December, 1933, p. 17.

${ }^{20}$ Cf. Section 4.

${ }^{21}$ Haberler, op. cit., Ch. III, 4, pp. 45-57.

${ }^{22}$ I gave an example in my paper "Econometric Business Cycle Research," Review of Economic Studies, Vol. 7, 1940, p. 83. 
(a) Coming to the proximate causes of the downturn as seen by the theories under discussion, Haberler mentions, first of all, ${ }^{23}$ the inability or unwillingness of the banking system to continue the expansion. As far as the banks show this inability by an increase in interest rates, it is included in our equation determining the interest rate. As far as an additional action of the banks, in particular by rationing credits, is meant, this would have to show itself in our equations on investment activity or on demand for credits by a deviation between actual and calculated series, especially at the top of the boom. The actual figures of, e.g., investment activity ought to be lower, by this rationing, than the calculated figures, where no account is taken of this influence. The same ought to be true for the amount of credit demanded. Something of this kind cannot, however, be discerned in the corresponding graphs. ${ }^{24}$ This is no straightforward proof of the absence of rationing, but a suggestion that it has perhaps not had much importance.

(b) Professor Hayek attaches much importance to a relative shift from investment to consumption in the later phases of the cycle. A comparison of the curves for consumption outlay and home-investment outlay for the United Kingdom does not show a regular behavior of this kind. In 1891 and 1908 there is, in fact, a high consumption outlay in comparison to investment, but in 1874,1884 , and 1901 there is nothing of this kind. The course of these two variables for the United States during the period 1919-1932 25 is about exactly parallel, showing no shift of the sort. The same is true for the Dutch figures in this period. Professor Hayek bases his statement on the fact, confirmed by our statistics, that total wages lag behind profits. There seems to be, however, the counteracting fact that consumption outlay by nonworkers shows a definite lag behind incomes. For the United States the reason of this lag appears to be the lag between profits and income paid out. ${ }^{26}$

(c) As another factor that tends to swell the demand for consumers' goods, Haberler mentions ${ }^{27}$ faulty bookkeeping methods, leading to paper profits. The presence of these is, for the United Kingdom and Holland, confirmed by our results; but it is another matter whether they tend to swell consumption towards the end of the boom. This would be true only if prices should rise very fast only at the end of the boom and not before; the figures do not confirm this hypothesis. It is, in fact, true for some minerals in some boom periods; but it is not true for the bulk of raw materials. It is still another question whether or not the phenome-

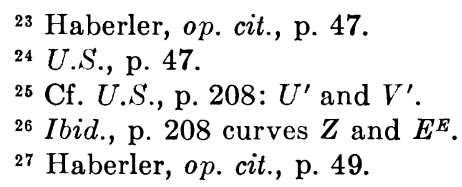


non of paper profits is a reason for the turning point to come. They are proportional to the rate of increase in prices, and, since prices move largely parallel to the general cycle, to the rate of increase in profits. The rate of increase has the tendency to show fluctuations preceding the fluctuations of profits themselves: the maximum rate of increase in a cyclic curve is attained before the maximum of the curve itself, since at that maximum the rate of increase is zero again. The paper profit element in profits therefore is already beginning to decline when the other elements are still rising and thus they are an early depressing tendency. Mathematically this works in exactly the same way as the acceleration principle.

7. The upturn. As an important reason for a revival Haberler mentions $^{28}$ the possibility that the natural rate of interest at once rises above the market rate, especially if the fall of prices comes to an end. This is in good accordance with our system, since a stop to the price fall means an increase in the rate of increase in prices, and this influences profit calculations favorably.

Summarizing, our impression of the monetary overinvestment theories is that their central statement that the difference between natural and market rate of interest regulates investment activity-if interpreted as we did-is reflected in our models. The emphasis laid on the market rate of interest seems to be somewhat exaggerated, the influence of changes in the natural rate underestimated. The thesis that market rates are changed deliberately is open to doubt, and so are the statements about credit rationing and about a shift towards consumption at the end of the boom.

\section{NONMONETARY OVERINVESTMENT THEORIES}

Following Haberler, we shall first discuss the theories of Spiethoff and Cassel. ${ }^{29}$

1. The fact, mentioned by Spiethoff, that sometimes consumption has fallen during an upswing, must not be taken too seriously as a proof that an increased investment activity is the necessary condition of an upturn. Consumption is, more than investment activity, influenced by crop yields, which show irregular fluctuations. It does not follow that the systematic forces making for consumption are not very important for the causation of the cycle.

A similar remark may be made with respect to the further argument that fluctuations in investment activity precede consumption fluctuations and therefore must be the "cause" of the cycle. Apart from the

${ }^{28}$ Ibid., p. 62.

${ }^{29}$ Ibid., pp. 72-85. 
doubt whether this lag actually exists, ${ }^{30}$ it has already been observed by the authors advocating the acceleration principle that investment activity still may be the consequence of the rate of increase of consumption, since the cycles in that rate of increase precede the cycles in investment activity.

2. Spiethoff also holds the theory that saving falls off at the end of the boom because of a rise in wages. We have already dealt with this matter in the preceding section, under $6 \mathrm{~b}$. He attaches more importance, however, to the overproduction of fixed capital goods. This overproduction in a sense is also an element of our scheme. Overproduction means a larger production than can be used economically. If there were no lag between orders and deliveries of capital goods, then an overproduction would not be possible: If there were no economic use for the goods, why order them? It is only since at the moment of ordering the market position is better than at the moment of delivery that overproduction can take place. This state of affairs is well described by Aftalion $^{31}$ in the parallel with the stove. In our scheme, the lag between ordering and delivery of capital goods is discounted in the lag between profits and consumption of investment goods. ${ }^{32}$

3. For the explanation of the upturn, Spiethoff points to new inventions and the discovery or opening of new markets. These phenomena are considered as external "disturbances," giving fresh impulses to the business system. The fact that Spiethoff does not hope much from automatic revival means, in our language, that he considers the damping degree of the systematic movements as rather large. Our results would suggest that he is somewhat too pessimistic in this respect.

4. At some places in his writings, Prof essor Spiethoff makes allusion to another possible cause of revival, viz., the so-called reinvestment or echo phenomenon. For reasons to be set out elsewhere we are also of the opinion that this phenomenon must play a certain role. ${ }^{33}$

5. There remains to be discussed, in this section, the acceleration principle. In its rough form the principle says that the quantity of investment goods required is proportional to the rate of increase in the production of consumers' goods. It is used in particular to demonstrate that the percentage fluctuations in investment-goods production are much larger than those in consumers'-goods production. A number of

${ }^{30} \mathrm{Cf}$. Section B, 5.

${ }^{31}$ It is to be doubted whether Aftalion should be reckoned-as he is by Haberler-among the theorists of the acceleration principle.

${ }^{32}$ U.S., p. 45.

${ }^{33}$ A recent contribution to a statistical proof of this phenomenon is given by J. Meuldijk, "Der Englische Schiffbau während der Periode 1870-1912 und das Problem des Ersatzbaues," Weltwirtschaftliches Archiv, Vol. 52, 1940, p. 524. 
qualifications have to be made. The principle is deduced from the hypothesis that production is always at full capacity; it then describes how capacity has to be adapted to demand for consumers' goods, which is considered as given. Apart from the impossibility of adapting capacity to rapidly falling volumes of production, there is the statistical fact that production is not always at full capacity, even in boom periods.

Taken rigorously, the principle would imply a lead, by about onequarter of a cycle, of investment-goods production ahead of consumers'goods production. Such a lead does not exist; moreover, the time shape of the curve of investment-goods production deviates considerably from the time shape of the curve representing the rate of increase in consumers'-goods production. Finally, the amplitude of these curves does not show the proportion required by the principle: the amplitude of investment-goods production is about one-half or less of what is required. ${ }^{34}$

Since the principle has sometimes been considered almost a tautology, the above conclusions need some further comment. In the long run it is probable indeed that the principle is satisfied. The short-run fluctuations in investment-goods production must be considered, however, only as attempts to regulate capacity. The ideal of this regulation may be the adaptation as set out by the acceleration principle. But since the adaptation must always be directed towards an unknown future demand for consumers' goods, it is only natural that errors may be committed. The entrepreneurs have to make some hypothesis about future development; that they base themselves on the actual situation of incomes and become more optimistic the higher these incomes, seems also quite conceivable. This, in fact, is the assumption made for the establishment of our "investment equation," ${ }_{35}$ which gives a much better fit than the acceleration principle.

If this view be accepted, the relative amplitude of the cyclic fluctuations in consumption-goods and investment-goods production must be explained otherwise, the more so since the proportion actually deviates from what the theory would require. We have tried to give another explanation in the previous section (under 5). Its chief element is something quite near to Mr. Keynes' multiplier concept, based on the propensities to consume and invest. We think this is more appropriate for the cyclic fluctuations.

In summary, our results suggest that neither investment activity nor consumption is leading, but that both depend on profit calculations:

${ }^{34}$ All this has been set out in my paper, "Statistical Evidence on the Acceleration Principle," Economica, Vol. 5, 1938, p. 164; cf. also A Method and its Application to Investment Activity, pp. 50-55.

${ }^{35}$ U.S., p. 45; cf. also, $A$ Method and its Application to Investment Activity. 
investment activity, since it is based on profit expectations and financial possibilities, which both depend on profit calculations; consumption, since it is based on disposable income, which also depends on profit calculations. Investment activity as well as consumption are lagging about one year behind calculated profits. Calculated profits are based not only on current production and prices, but also on the rate of increase in prices, whose cycles precede those of prices. Both consumption and investment activity are also dependent on random fluctuations: consumption on crop yields and investment activity on inventions. Such random disturbances may, together with the consequences of the echo principle, stimulate the cycle again after it has been damping down.

\section{CHANGES IN COST, HORIZONTAL MALADJUSTMENTS, AND OVERINDEBTEDNESS}

1. Changes in cost are reflected in our models in the price equations. ${ }^{36}$ In particular those relating to home prices tell us that marginal cost and hence prices rise if the volume of production goes up. In their turn, these higher prices reduce the quantity demanded of the corresponding goods. ${ }^{37}$ It does not follow, however, that they also reduce the value of demand. The elasticity of demand is below unity for each of these categories and therefore total value is not diminishing as a consequence of a rise in costs. For this reason we agree with Haberler when he does not attach much importance to cost changes for an explanation of cycles.

2. Horizontal maladjustments have not been given a prominent place in our system of relations. The reason is that not very much evidence is available for serious horizontal maladjustments. As a rule all branches-industries of food products as well as clothing and durable goods, e.g.- - show the cycles in a similar way. Shifts from one good to another occur either as a consequence of a long-term process of replacement (cotton by artificial silk) or as a consequence of random crop fluctuations (year-to-year changes in cotton consumption), which both have not very much to do with systematic cyclical changes.

3. Overindebtedness also has no place in our scheme. One reason is that total (long-term) debts of industry, as far as they have been measured statistically, do not seem to have changed very violently. Now such rapid fluctuations as business cycles can only be explained by the interaction of rapidly changing phenomena. Slowly changing variables can only have a certain significance as conditioning factors, not as direct causes.

Another reason for not having represented by one of our equations

${ }^{36}$ U.S., Ch. III; Holl., Section I, C.

${ }^{37}$ U.S., Ch. II; Holl., pp. 23 and 31. 
the particular mechanism meant by Professor Fisher we may present in the following way: The mechanism through which high debts tend to provoke a crisis is that of distress selling. In the language of our relations this would mean that some of the price equations should show deviations particularly in crisis periods. Actual prices should be systematically lower than calculated prices in times of crises, pointing to a tendency of underbidding the market more than usually. No systematic feature of this kind could be detected. Again we do not pretend to have proved that nothing of this kind exists; but we suggest that it was not of much importance, at least in the periods and countries studied and for the economies as a whole.

\section{E. UNDERCONSUMPTION THEORIES}

1. Professor Haberler, in his chapter on these theories, rightly begins by rejecting a number of formulations of these theories that deal only with secular phenomena. "It is hopeless," he says, "to explain the business cycle without taking account of the cumulative nature of the 'short-run' processes of expansion and contraction."'38 We want to stress this also with respect to other theories using secular changes to explain cycles, e.g., theories that explain revival by pointing to population growth. ${ }^{39}$

As the heart of the "underconsumption theory" Haberler considers the statement that an increase in savings means a reduction of the demand for consumers' goods and an increase in investment, and hence, in the supply of consumers' goods. Therefore, the adherents of this theory say, only a decrease in savings will be favorable to the general business situation and may postpone the crisis.

Haberler seems to admit that this theory is possible; but he very much stresses, on the other hand, the possibility seen by the overinvestment theories, viz., that more savings are necessary as a consequence of an increased roundabout way of production. In this train of thought, higher savings are necessary at the moment of the crisis, since otherwise a part of the newly ordered investment goods (necessary, inter alia, because of the longer roundabout way) could not be "taken over" and production in these stages would have to be stopped. At the same time it would not matter if less were available for consumption, since production of consumers' goods is decreased: workers from these branches

${ }^{38}$ Haberler, op. cit., p. 122.

${ }^{39}$ This may be shown mathematically: Suppose we have a system of difference equations of which the solution corresponds with a periodic movement. If we add to anyone of these equations a trend term-i.e., the influence of some phenomenon, showing only secular movements - then only the trend of the resulting movement is different from the original movement. Nothing changes in the period and damping degree of that movement. 
have been attracted by the investment-goods industries. According to this theory, an increase in savings is the only way of postponing the crisis.

2. Two relations are of outstanding importance for the understanding of these problems, viz., that between savings and investment and that between the capacity to produce consumers' goods and the actual production of these goods.

The first relation, that between savings and investments-where these words are used in the Robertsonian sense ${ }^{40}$ - depends primarily on the elasticity of the credit supply. If that supply is fairly elastic - as we found it to be as a rule-investments may easily surpass savings and a decrease in savings need not mean an equal decrease in investments. As a rule it will lead to a decrease in investments that is smaller than the decrease in savings. Since the increase in consumption outlay to which a decrease in savings is equivalent equals that decrease in savings, total outlay for consumers' goods and investment goods together will increase. And if a crisis would have come without that decrease in savings, it will be postponed by that decrease.

Three objections may be made:

(i) If consumers'-goods industries are fully occupied, an increase in consumption outlay will not lead to a higher volume of production. If, at the same time, investment-goods industries are not fully occupied, total volume of production will be increased by an increase in savings, even if total outlay goes down.

Our answer is that as a rule the situation at the top of the boom is different. Investment-goods industries are occupied to a higher degree than consumers'-goods industries. By the way it may be observed that there is no evidence that, in the period preceding the turning point, workers are taken off from consumers'-goods industries to any appreciable extent as far as our knowledge of these matters goes.

(ii) The second objection may be that if every increase in consumption outlay yields a higher national income, why not stop all saving and consume all? Our answer is that if the only object were to increase total outlay, this procedure would certainly work well. There are other consequences of it which are less preferable: it would lead to credit inflation. The problem put by Haberler in order to clarify the controversy is, however, restricted: the only question being how a crisis may be postponed. This we think is actually obtained only by an increase in consumption outlay. In other words, in this respect we adhere to the underconsumption theory.

(iii) The third objection may be that at the very moment of the turning point the credit supply is completely inelastic and that this is the reason-in Hayek's theory-for the breakdown to come. Our

${ }^{40}$ Cf. Haberler, op. cit., Ch. VIII, in particular p. 177. 
answer is that for some of the pre-1914 crises this seems actually to have been the case; but that even then total outlay would remain equal only if savings should suddenly decrease: even then the crisis would not be hastened by such a shift; and a postponement of it by an increase in savings is not probable.

3 . The second relation that deserves special attention with respect to the oversaving-undersaving controversy is that between the capacity to produce consumers' goods and the actual volume of production of these goods. Our results ${ }^{41}$ point to a very high elasticity of supply. Practically this means that demand determines the quantity produced. It follows that the volume of production need not necessarily increase if the capacity of production is increased. Theories ascribing the crisis to the sudden "pouring out of consumers' goods at the moment that the raw capital goods are completed" 42 therefore do not seem to be realistic pictures of the events. They presuppose a low elasticity of supply. Moreover, they suggest that there would be one "moment" when new capital goods are completed in particularly large quantities. The increase in capacity is, for the economy as a whole, a very smooth process, however.

In order to describe the relation here under discussion in other terms, we may say that the movements of total capacity available--however defined-are very slow, whereas those of the demand factors, such as incomes, are much more violent. For this reason, in connection with the high elasticity of supply, it is very improbable that changes in the capacity are the reasons for the fluctuations in volume of production, and very likely that the changes in demand explain them. In other words, it is not "overproduction" that explains the crisis.

The relation between the total of investment goods present at a certain moment and the possible output of consumers' goods is also influenced by the length of the roundabout way. With a longer roundabout way, less consumers' goods will be yielded by the same quantity of investment goods than with a shorter roundabout way. As we have already pointed out, we do not think that the changes in the roundabout way are very sensitive to changes in the interest rate, at least in the short run. Therefore we think that theories neglecting these changes will be more realistic than theories explaining the whole phenomenon of the cycle by it. We do not pretend, however, to have proved this statistically.

4. For a good understanding of the questions under discussion it is useful also to repeat some remarks on the time order of events as we found them to exist roughly in the United Kingdom between 1870 and 1914. The lag between investment-goods consumption and its deter-

${ }^{41}$ U.S., Ch. III; Holl., Section IC.

${ }^{2}$ Cf. Haberler, op. cit., p. 135. 
minants is of the order of one year. It seems unrealistic then to ascribe the boom in investment-goods production chiefly to the low interest rates prevailing at the beginning of the boom. This would imply an average lag of some four years. Lags of four years may occur in some cases, but it is hard to believe that they are representative for the majority of investment acts.

If this is so, and a shorter lag must hence be assumed to prevail, then a shortening of the roundabout way during the last two or three years of the boom would follow theoretically rather than a lengthening. Interest rates begin to rise shortly after the upturn. The duration of the upturn may on the average be taken at four to five years. One year after the interest rate begins to rise, its effect on investment has worked through. A rise in interest rates means a shortening of the roundabout way. There still remain two to three years of the boom before the turning point comes. During these years the roundabout way would be shortening rather than increasing.

Further the shift towards more consumption and less saving towards the end of the boom, to which allusion is of ten made, does not seem to occur regularly. ${ }^{43}$

5. In summary, our chief statements concerning the underconsumption theories are that: (i) as long as there is some elasticity, however small, in the credit supply, any increase in consumption outlay will lead to an increase in total outlay; only with a completely inelastic credit supply will total outlay remain unchanged; and that (ii) the supply of consumers' goods adapts itself to demand; hence, a turning point in production must be ascribed to a change in demand factors rather than in supply factors. These two statements may be given in the following short and therefore dangerous form: in the controversy between underconsumption and undersaving theory we adhere to the underconsumption theory; in the controversy between the underconsumption and the overproduction versions of that theory, we adhere to the underconsumption version.

\section{F. SUMMARY}

Let us now try to summarize our chief findings, negative as well as positive.

Our chief negative results may be given under two headings: First, a number of theories seem to start from an erroneous factual basis. Examples are:

(i) The assumption that there is a systematic lag between the cycles in the production of consumers' goods and investment goods.

(ii) The assumption that there is a systematic shift towards the end of the boom, from investment to consumption.

${ }^{43}$ Cf. Section B, 6b, and Section C, 2. 
(iii) The assumption that the cyclic movements in investment-goods production may be explained by the acceleration principle.

(iv) The assumption that fluctuations in the rate of interest have a considerable influence on the fluctuations in commodity stocks.

We are also skeptical about the prominent place given in some theories to the rationing, in boom periods, of credits and to the opinion that the rate of interest would be determined by "deliberate action of the bankers."

Secondly we have serious methodological objections against the methods of research used by some theorists:

(i) We doubt whether the notions of roundabout way of production and of natural rate of interest are useful instruments of analysis.

(ii) Too little attention is paid, as a rule, to the quantitative aspects of the explanation of cyclic movements. As we have set out already at other opportunities there are numerous examples of theories that are indeterminate if not formulated quantitatively. The same qualitative mutual dependency of a system of variables leads to a cyclic movement for some sets of values of the coefficients and to a noncyclic movement for another set of values.

(iii) Another criticism may be added to this list, viz., one concerning the well-known controversy whether more saving or more consumption will delay the outbreak of a crisis. We adhere to those who consider this controversy as nonessential. The essential issue is the choice between hoarding and spending rather than between saving and consuming.

On the other hand, a number of elements of various theories have been found "confirmed" by our analysis. The reader should be reminded, however, that such confirmations are no proof of any theory. They only mean that the theories concerned are not contradictory to the facts. The following elements of different theories have been confirmed in that restricted sense:

(i) The chief elements of the "cumulative process": Increases in consumption outlay and investment activity lead to higher incomes. Higher incomes themselves lead to higher consumption, ${ }^{44}$ investment, and prices. An increase in prices yields a positive contribution to income calculations.

(ii) Investment activity may be said to be regulated by the difference between profit rate and interest rate. The fluctuations in profit rate are more important than those in interest rates, however.

(iii) The supply of money is found to be elastic in the United Kingdom and fairly elastic in the United States, where an elasticity of 0.65 was found.

(iv) The supply of manufactured consumers' goods is found to be

${ }^{44}$ The notion of marginal propensity to consume appears to be particularly easy for the description of these interrelations. 
very elastic; that of raw materials and that of investment goods in boom times is less elastic. This explains the well-known fact that prices of raw materials and investment goods rise in a greater proportion than prices of finished consumers' goods.

(v) An element of minor importance is the dependency of money circulation on wage income.

(vi) The result that the fluctuations in short-term interest rates depend to a large extent on the fluctuations in the gold stock of the central banks.

Our positive findings have not all been discussed in the foregoing, since the primary object was to review given theories. In this summary we want, however, also to include such conclusions as do not bear on particular theories, in order to give an impression of our own view of the chief elements in an explanation of the cycle.

(i) It is not necessary to explain the turning point by any sort of "saturation," by which we mean such phenomena as increasing inelasticity (rationing), bottlenecks, and the like.

(ii) The turning point may be explained by the combined action of some acceleration principle and one or more lags. ${ }^{45} \mathrm{By}$ an acceleration principle we mean quite generally the influence of the rate of increase of any variable on that variable itself.

(iii) As we have stated already, we reject the acceleration principle in the narrower sense, i.e., for the explanation of the production of durable investment goods. But there seems to be a considerable influence of the rate of increase in raw-material prices or of the rate of increase in share prices on profit calculations and hence on general activity. This influence works in quite the same way, as far as the mathematical aspect is concerned, and may well explain the occurrence of cyclic movements without the help of "saturation" [cf. (i) above].

(iv) Some of the lags that play an important role in the explanation of short-run fluctuations are the lag between incomes and outlay and that between quantity demanded and prices. The first lag depends on technical elements in income formation (dividend payments, e.g.) and on a psychological lag in spending habits; the second is characteristic for the reactions of the producer to changes in his market: he will not immediately be able to discern fundamental changes from temporary ones and will therefore delay an adjustment of his price to a changed situation; moreover he will try to sell old stocks at old prices.

\section{Rotterdam School of Economics}

${ }^{45}$ Of course a turning point may always be explained by an exogenous change. Professor Frisch has developed serious arguments in favor of the statement that all turning points are to be understood in this way. Cf. T. Haavelmo, "The Inadequacy of Testing Dynamic Theory . . . " Econometrics, Vol. 8, October, 1940, pp. $312-321$. 
http://www.jstor.org

\title{
LINKED CITATIONS \\ - Page 1 of 1 -
}

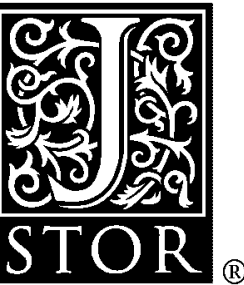

You have printed the following article:

\section{Critical Remarks on Some Business-Cycle Theories}

J. Tinbergen

Econometrica, Vol. 10, No. 2. (Apr., 1942), pp. 129-146.

Stable URL:

http://links.jstor.org/sici?sici=0012-9682\%28194204\%2910\%3A2\%3C129\%3ACROSBT\%3E2.0.CO\%3B2-0

This article references the following linked citations. If you are trying to access articles from an off-campus location, you may be required to first logon via your library web site to access JSTOR. Please visit your library's website or contact a librarian to learn about options for remote access to JSTOR.

\section{[Footnotes]}

\author{
${ }^{19}$ Annual Survey: Suggestions on Quantitative Business Cycle Theory \\ J. Tinbergen \\ Econometrica, Vol. 3, No. 3. (Jul., 1935), pp. 241-308. \\ Stable URL: \\ http://links.jstor.org/sici?sici=0012-9682\%28193507\%293\%3A3\%3C241\%3AASSOQB\%3E2.0.CO\%3B2-B \\ ${ }^{22}$ Econometric Business Cycle Research
}

J. Tinbergen

The Review of Economic Studies, Vol. 7, No. 2. (Feb., 1940), pp. 73-90.

Stable URL:

http://links.jstor.org/sici?sici=0034-6527\%28194002\%297\%3A2\%3C73\%3AEBCR\%3E2.0.CO\%3B2-4

\section{${ }^{34}$ Statistical Evidence on the Acceleration Principle}

J. Tinbergen

Economica, New Series, Vol. 5, No. 18. (May, 1938), pp. 164-176.

Stable URL:

http://links.jstor.org/sici?sici=0013-0427\%28193805\%292\%3A5\%3A18\%3C164\%3ASEOTAP\%3E2.0.CO\%3B2-H

\section{${ }^{45}$ The Inadequacy of Testing Dynamic Theory by Comparing Theoretical Solutions and Observed Cycles}

Trygve Haavelmo

Econometrica, Vol. 8, No. 4. (Oct., 1940), pp. 312-321.

Stable URL:

http://links.jstor.org/sici?sici=0012-9682\%28194010\%298\%3A4\%3C312\%3ATIOTDT\%3E2.0.CO\%3B2-E

NOTE: The reference numbering from the original has been maintained in this citation list. 